\title{
The screw gene encodes a ubiquitously expressed member of the TGF- $\beta$ family required for specification of dorsal cell fates in the Drosophila embryo
}

\author{
Kavita Arora, ${ }^{1}$ Michael S. Levine, ${ }^{2}$ and Michael B. O'Connor ${ }^{1,3}$ \\ ${ }^{1}$ Department of Molecular Biology and Biochemistry and ${ }^{3}$ The Developmental Biology Center, University of California \\ Irvine, Irvine, California 92717 USA, ${ }^{2}$ Department of Biology, University of California San Diego, La Jolla, California \\ 93093 USA
}

The decapentaplegic (dpp) gene product, a TGF- $\beta$ related ligand, acts as an extracellular morphogen to establish at least two cellular response thresholds within the dorsal half of the Drosophila embryo. Null mutations in the screw (scw) gene are phenotypically similar to moderate dpp mutants and cause dorsal cells to adopt ventral fates. We show that scw encodes a novel TGF- $\beta$ protein and is an integral part of the signal that specifies dorsal pattern. Although scw is expressed uniformly during blastoderm stages, its effect on development appears graded and is restricted to the dorsal side of the embryo. Our results indicate that DPP activity alone is insufficient to specify different dorsal cell fates. We propose that SCW and DPP act together to establish distinct response boundaries within the dorsal half of the embryo, perhaps by forming heterodimers that have higher activity than homodimers of either molecule alone.

[Key Words: Dorsal-ventral pattern; BMP; signal transduction]

Received June 28, 1994; revised version accepted September 14, 1994.

A set of zygotically active genes, short gastrulation $(\operatorname{sog})$, twisted gastrulation (tsg), zerknüllt (zen), shrew (srw), tolloid (tld), screw (scw), and decapentaplegic (dpp) are required for pattern specification in the dorsal half of the Drosophila embryo (Jürgens et al. 1984; Nüsslein-Volhard et al. 1984; Wakimoto et al. 1984; Wieschaus et al. 1984; Zusman and Wieschaus 1985; Irish and Gelbart 1987). Null alleles of these genes produce related mutant phenotypes that vary in severity but are characterized by the loss of dorsal pattern elements and an expansion of structures that normally derive from lateral or ventral regions of the fate map (Arora and Nüsslein-Volhard 1992). Genetic analysis suggests that these zygotic genes are involved in establishing, or responding to, a morphogen gradient that has its highest point in the dorsal-most region (Ferguson and Anderson 1992a; Wharton et al. 1993).

Several lines of evidence suggest that $d p p$ functions as the primary signal in the dorsal half of the embryo. Null mutations in $d p p$ result in the most severe phenotype, that is, the loss of all dorsal structures. In addition, mutations in $d p p$ are lethal even in heterozygotes, indicating that the level of $d p p$ product is critical for development (Irish and Gelbart 1987). Recent experiments in which $d p p$ gene dosage was manipulated have revealed that changes in $d p p$ concentration cause cells to adopt different dorsal cell fates (Ferguson and Anderson 1992a;
Wharton et al. 1993). These studies provide compelling evidence that DPP behaves as a concentration-dependent morphogen.

DPP belongs to the transforming growth factor- $\beta$ (TGF- $\beta$ ) family of secreted molecules and is related most closely to the bone morphogenetic proteins BMP-2 and BMP-4 (Padgett et al. 1987; Wozney et al. 1988). Because $d p p$ message is uniformly distributed in the dorsal $40 \%$ of the embryo, it is believed that a gradient of $d p p$ protein or activity is established post-transcriptionally (Ferguson and Anderson 1992a; Wharton et al. 1993).

Two other genes, $s c w$ and $t l d$, play a major role in the specification of dorsal cells and appear to be involved in regulating DPP activity (Shimell et al. 1991; Arora and Nüsslein-Volhard 1992; Ferguson and Anderson 1992b). Mutations in these genes cause premature loss of zen expression, a downstream gene that specifies the dorsal most cell type, the amnioserosa (Rushlow and Levine 1990, Ray et al. 1991). Extra copies of the $d p p$ gene can suppress the phenotype of partial loss-of-function mutations in scw and tld but not that of mutations in zen. Thus, it is likely that $s c w$ and tld act upstream of, or in conjunction with, $d p p$ to enhance its activity (Ferguson and Anderson 1992b). Support for this view comes from the fact that $t$ ld encodes a metalloprotease that shares extensive sequence similarity with mammalian BMP-1 (Shimell et al. 1991). BMP-1 was originally identified in 
demineralized bone extracts as part of a complex that includes BMP-2, the mammalian DPP homolog (Wozney et al. 1988), and it has been suggested that TLD may modulate DPP activity proteolytically (Shimell et al. 1991).

We have cloned and characterized the $s \mathrm{cw}$ gene and show that it encodes a novel BMP-like member of the TGF- $\beta$ superfamily. Thus, it is likely that SCW functions as an intercellular signaling molecule. Surprisingly, although the $s c w$ transcript is expressed ubiquitously in the early embryo, SCW activity is required only in dorsal cells. We speculate that the activity of SCW is spatially restricted by its interaction with either TLD or DPP. We propose that the combinatorial action of both SCW and DPP, perhaps as heterodimers, is required to specify the entire range of cell fates in the dorsal half of the embryo. This is an alternative to the single morphogen gradient model in which DPP activity alone specifies different dorsal cell fates. Our demonstration that multiple TGF- $\beta$-like signaling molecules are involved in early dorsal patterning in the embryo suggests many parallels with mesoderm patterning in Xenopus and osteogenesis in vertebrates (Sive 1993; Kingsley 1994a).

\section{Results}

scw affects the ability of dorsal cells to differentiate amnioserosa and dorsal cuticle in a graded manner

The scw gene was identified in a screen for second chromosome zygotic lethal mutations that affect embryonic patterning (Nüsslein-Volhard et al. 1984). Blastoderm cells in the presumptive thoracic and abdominal regions of the wild-type embryo differentiate into one of four cell types according to their position along the dorsoventral (DV) axis: Ventral-most cells invaginate to give rise to the mesoderm; ventrolateral cells form the nervous system and the ventral ectoderm; dorsolateral cells differentiate into dorsal ectoderm; and the cells at the dorsalmost position become the extra embryonic amnioserosa (Fig. 1; Lohs-Schardin et al. 1979). Mutations in scw cause an expansion of the ventral ectoderm at the expense of amnioserosa and part of the dorsal ectoderm, indicating that the gene is required for normal dorsal development.

Different $s c w$ alleles can be ordered into a phenotypic series that shows a progressive loss of dorsal structures (Arora and Nüsslein-Volhard 1992). Cuticle preparations of the weakest mutant alleles indicate a loss of pharyngeal skeleton and other dorsally derived structures such as the antennomaxillary sense organs and the cirri. The filzkörper, a paired dorsolaterally derived structure in the tail of the larvae, are reduced or absent (Jürgens et al. 1986; Jürgens 1987; Fig. 1A,B). In scw null embryos the amnioserosa, as well as a significant part of the dorsal ectoderm, are lost. The change in dorsal cell fate in mutant embryos is reflected in the increased width of the ventral denticle bands (Fig. $1 \mathrm{~B}, \mathrm{C}$ ). By comparison, in null
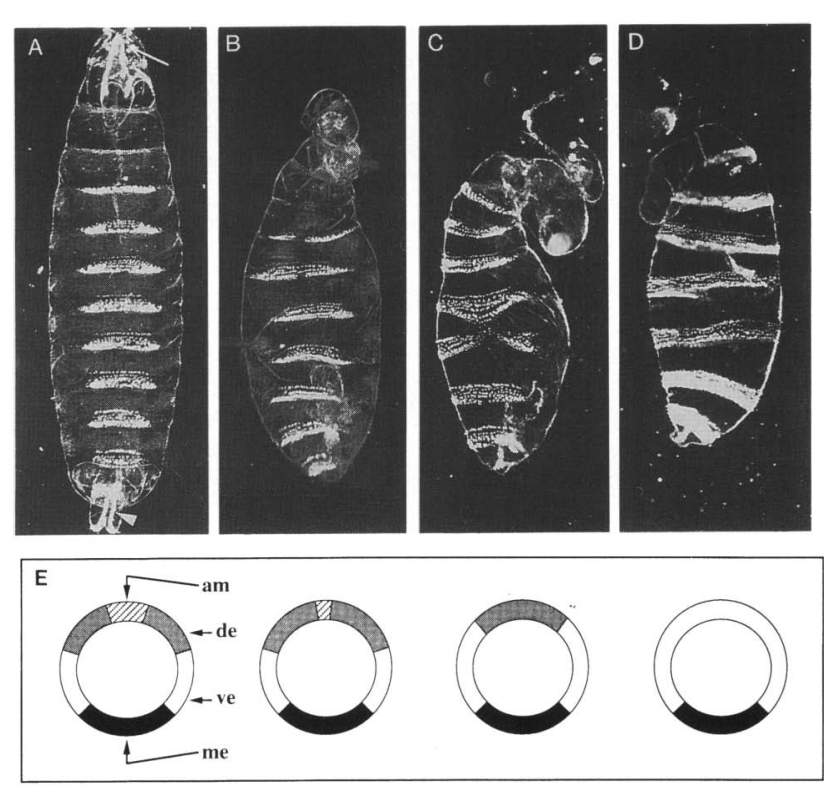

Figure 1. $s c w$ mutations result in partial ventralization of the blastoderm fate map. Anterior is up and ventral side is facing the viewer. $(A)$ Cuticle of a wild-type larva. The internal pharyngeal skeleton that derives from anterior dorsal regions is marked with an arrow. The dorsolaterally derived filzkörper are marked with an arrowhead. (B) Cuticle of a $S C W^{I G 76}$ mutant illustrating the weak ventralized phenotype. Loss of the cephalopharyngeal structures results in the unusual morphology of the head. The terminal structures are displaced into the interior of the embryo because of defects in germ-band movement. Filzkörper are fused. Slight expansion of the ventral denticle belts is apparent, especially in the anterior abdominal segments. $(C)$ Cuticle of a $s c w^{S 12}$ mutant. This allele represents the null phenotype caused by mutations at this locus. Anterior dorsal structures are missing, as is the amnioserosa. The filzkörper are significantly reduced. The loss of dorsal pattern is accompanied by expansion of ventral structures. Ventral denticle belts are extended laterally. $(D)$ Cuticle of a $d p p^{H 48}$ homozygous mutant. These embryos do not differentiate any dorsal cuticle, instead dorsal cells differentiate bands of ventral denticles like ventrolateral cells in a wild-type larvae. $(E)$ Schematic drawings of the blastoderm fate maps of the wild-type and mutant embryos shown in $A-D$. (am) Amnioserosa; (de) dorsal ectoderm; (ve) ventral ectoderm; (me) mesoderm.

$d p p$ embryos, the entire dorsal ectoderm is lost and all dorsal cells differentiate as ventral ectoderm (Fig. 1D; Irish and Gelbart 1987).

Mutations in $s c w$ affect embryonic pattern in a graded manner. This is demonstrated most dramatically by the progressive loss of the amnioserosa. A wild-type embryo differentiates $\sim 200$ amnioserosa cells (Fig. 2A). However, embryos derived from $s c w$ alleles of increasing phenotypic strength have from 120 cells to only a few amnioserosa cells (Fig. 2B,C). The most severe $s c w$ alleles do not differentiate any amnioserosa (Fig. 2D). The graded pattern defects in $s c w$ mutants are very similar to those that have been described for partial loss-of-function alleles of $d p p$ (Wharton et al. 1993), suggesting that these two genes may act in a common process. 


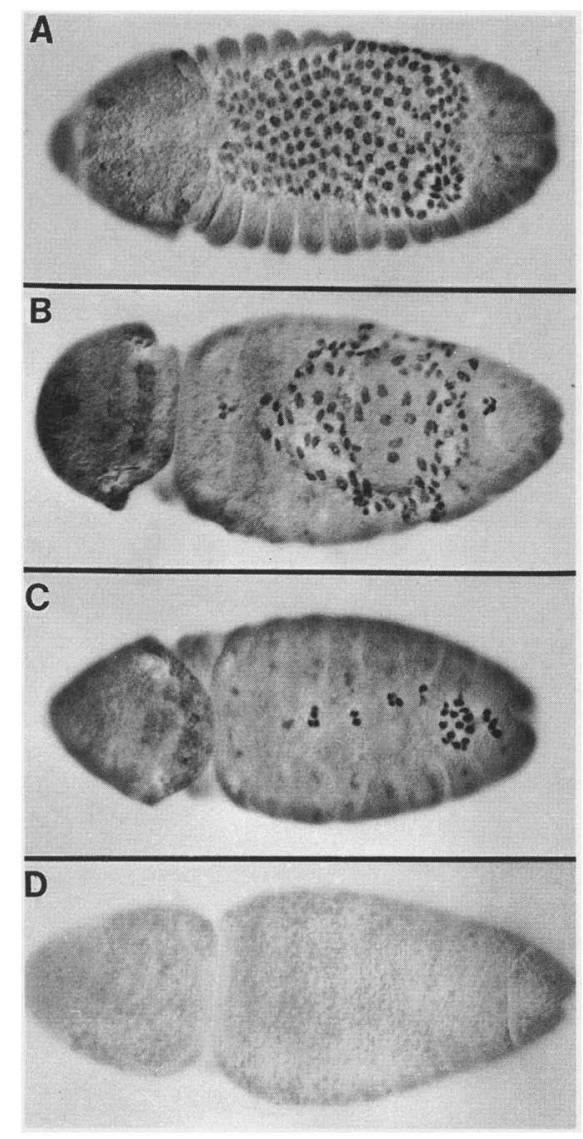

Figure 2. Partial loss-of-function $s c w$ alleles result in progressive deletion of the amnioserosa. Embryos have been immunostained using an anti- $\mathrm{Kr}$ antibody to detect amnioserosa cells. All embryos are oriented anterior to the left and dorsal up. $(A)$ Lateral view of a wild-type stage 13 embryo (staging according to Campos-Ortega and Hartenstein 1985). Mutant embryos representing partial loss-of-function alleles $s c W^{I G 76}(B), s c w^{\circ 5}(C)$, and $s c w^{s 12}(D)$. In the wild-type embryos, typically 200 cells stain with the anti-Kr antibody. The mutant embryos show a progressive reduction in the number of cells fated to form the dorsal-most pattern element, the amnioserosa. There is some variability in the amnioserosa phenotype. The embryos shown here reflect the phenotype of the majority of embryos in an egg lay from the respective allele.

The first morphological evidence of altered development in scw mutants is seen early in embryogenesis at the beginning of gastrulation (Arora and Nüsslein-Volhard 1992). This places the time of requirement for $s c w$ function at or prior to gastrulation. Fate mapping studies in mutant embryos have shown that the loss of dorsal structures does not result from cell death but is caused by a change in cell fate such that dorsally located cells behave like cells from a ventral position in a wild-type embryo (Arora and Nüsslein-Volhard 1992). Taken together, the phenotypic analysis demonstrates that $s C W$ gene function is not simply required for the differentiation of a specific pattern element but, rather, must be involved in organizing the overall pattern within the dorsal region of the embryo.

\section{Genetic and molecular mapping of the scw locus}

We first localized $s c w$ to the polytene band 38A1,2 on the second chromosome by complementation mapping using deficiency chromosomes (data not shown). Two overlapping deficiencies, $D f(2 L) O D 16$ and $D f(2 L) s c w$ [E1r2], fail to complement mutations in $s c w$, thus positioning the $s c w$ locus in the interval defined by the distal breakpoint of $D f(2 L) O D 16$ and the proximal breakpoint of $D f(2 L) s c w[E 1 r 2]$ (Fig. 3A). Molecular entry into this region was provided by a DNA clone corresponding to the gene brain-specific-homeobox, which maps within $D f(2 L) O D 16$ (Jones and McGinnis 1993). A total of $\sim 120$ $\mathrm{kb}$ of genomic DNA distal to the starting clone was isolated from a genomic library of wild-type Drosophila DNA. The deficiency $D f(2 L)$ pr65 was used to orient the direction of the walk (Jones and McGinnis 1993; data not shown). Mapping and hybridization experiments were used to identify the distal breakpoint of $D f(2 L) O D 16$ and the proximal breakpoint of $D f(2 L) s c w[E 1 r 2]$. These breakpoints define an $\sim 50-\mathrm{kb}$ interval that must contain at least a part of the $s c w$ gene (Fig. 3A).

\section{Molecular identification of the scw gene}

Three different transcription units were identified in the $\sim 50-\mathrm{kb}$ interval between the two breakpoints using reverse Northern blots (Fig. 3A). Genomic fragments from the walk were used to isolate cDNA clones corresponding to these transcribed regions. Full-length cDNA representatives of all but the longest $(7.4 \mathrm{~kb})$ of these transcripts were obtained from 0 - to 4 -hr cDNA libraries, and their positions on the genomic map were determined by restriction enzyme analysis and hybridization experiments (Fig. 3A). The 7.4-kb message corresponds to the previously identified dlar gene (Streuli et al. 1989; Saito and Streuli 1991). The dlar transcription unit is $\sim 90 \mathrm{~kb}$ long and contains 16 introns (N. Krueger and H. Saito, pers. comm.). This gene spans both deficiency breakpoints that define the minimal $s c w$ region. A second class of cDNAs maps within the fourth intron of the dlar gene and is transcribed in the opposite direction with respect to dlar. The third cDNA species from the region abuts the proximal breakpoint of $D f(2 L) s c w[E 1 r 2]$.

To determine which of the three candidate transcripts encoded $s c w$, the genomic regions corresponding to the $1.4-\mathrm{kb}$ and the $3.0-\mathrm{kb} \mathrm{cDNAs}$ were cloned into the $\mathrm{P}$ element vector $\mathrm{pCaSpeR}$ and inserted into the Drosophila genome by $\mathrm{P}$ element-mediated transformation (Fig. 3A, Rubin and Spradling 1982; Pirrotta 1988). The 7.4-kb dlar cDNA was cloned into pCaSpeR-hsp83 and the pCaSpeR-hsp70 vectors, which place the cDNA under control of the hsp 83 and the heat shock-inducible hsp70 promoter, respectively (Pirrotta 1988; Govind et al. 1993). Several independent transformant lines were obtained for each construct and tested for their ability to rescue $s c w$ mutants. Only constructs that included the 

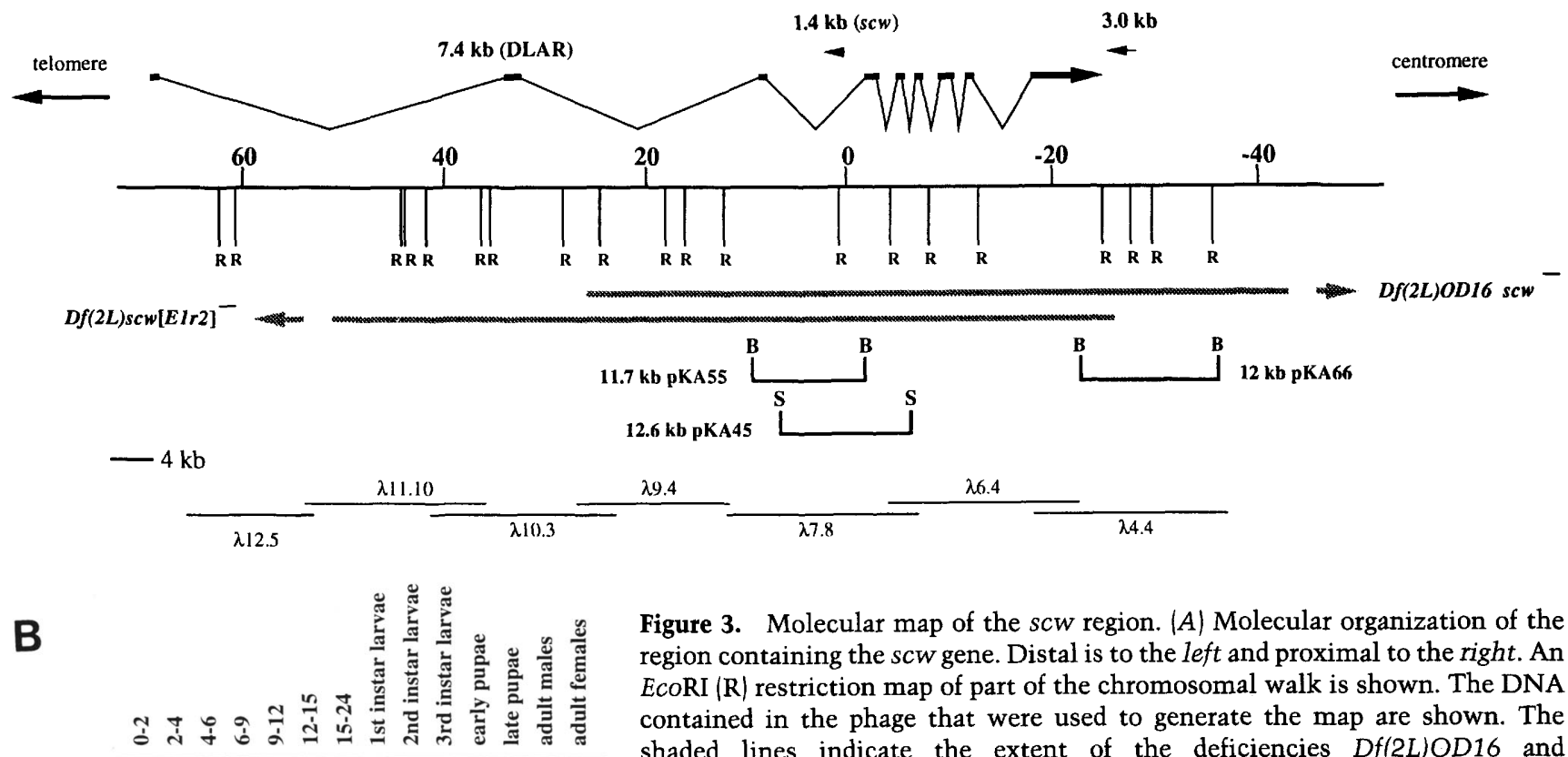

Figure 3. Molecular map of the $s c w$ region. (A) Molecular organization of the region containing the scw gene. Distal is to the left and proximal to the right. An EcoRI (R) restriction map of part of the chromosomal walk is shown. The DNA contained in the phage that were used to generate the map are shown. The shaded lines indicate the extent of the deficiencies $D f(2 L) O D 16$ and

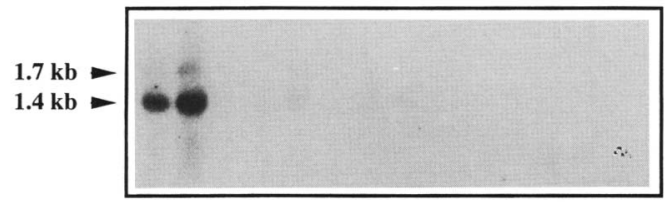
$D f(2 L) s c w$ [E1r2] (Raftery et al. 1994; see Materials and methods). The heavy black arrows above the restriction map mark the positions of the three cDNAs that map to the region of overlap between the breakpoints. (0) The $5^{\prime}$ position of the scw cDNA. Position of the dlar introns are approximate, and a number of small introns are not shown (based on N. Krueger and H. Saito, pers. comm.). The black bars indicate the genomic fragments used for the $\mathrm{P}$ element rescue experiments [(B) BamHI; (S) SalI]. (B) Developmental profile of $s c w$ transcripts.

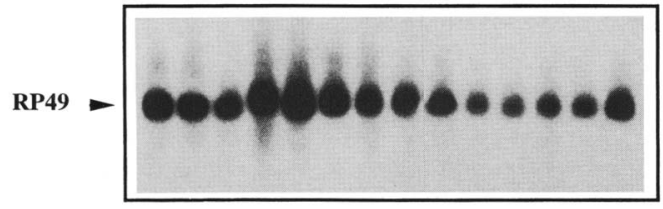
A Northern blot of RNA from the different stages indicated was probed with the scw-2A cDNA and RP49 ribosomal protein gene (control for loading). Two scw transcripts, $1.4-\mathrm{kb}$ and $1.7-\mathrm{kb}$ in size, are detected. Both transcripts are also detected by scw-N cDNA clone. On prolonged exposure very low levels of the 1.4-kb scw transcript are visible at all stages (data not shown).

1.4-kb cDNA were capable of rescuing homozygous $s c w$ mutant embryos to viability (Fig. $3 \mathrm{~A}$ ). We concluded that the entire $s c w$ gene is contained within the $7.5-\mathrm{kb}$ genomic region defined by the overlap between the two constructs and that the 1.4-kb cDNA is sufficient for $s c w$ function.

To determine the temporal pattern of $s c w$ expression, the 1.4-kb cDNA was used as a probe on developmental Northern blots. Two transcripts of 1.4 and $1.7 \mathrm{~kb}$ were identified (Fig. 3B). The 1.4-kb transcript is highly abundant in embryos at 2-4 hr of development, consistent with its early requirement in the embryo prior to the onset of gastrulation (Arora and Nüsslein-Volhard 1992). Prolonged exposure reveals a very low level of the 1.4-kb transcript at all embryonic stages (data not shown). The $1.7-\mathrm{kb}$ transcript is significantly less abundant and is seen only in the 2- to 4-hr lane. Transcripts seen in the 0to 2-hr lane are attributed to early zygotic transcription rather than to maternal contribution, as the lane containing RNA derived from female adults shows no detectable signal.
DNA sequence and conceptual translation of the scw gene

The complete nucleotide sequence of one scw cDNA isolate (scw-2A) accounts for the first 1413 bp shown in Figure 4A. The length of the cDNA is in close agreement with the transcript size of $1.4 \mathrm{~kb}$ observed on the Northern blots. Another isolate ( $\mathrm{scw}-\mathrm{N}$ ) is identical to scw-2A in the region of overlap ( $1.3 \mathrm{~kb}$ ) but is $306 \mathrm{bp}$ longer at the $3^{\prime}$ end (Fig. 4A), suggesting that it may correspond to the $1.7-\mathrm{kb}$ message on the Northern blot. The cDNA sequence contains a single large open reading frame (ORF) of 1200 nucleotides, flanked by $114 \mathrm{bp}$ of $5^{\prime}$-untranslated sequences and $405 \mathrm{bp}$ of $3^{\prime}$-untranslated sequences.

The first in-frame methionine codon matches the Drosophila translation start consensus of $\mathrm{ANN} / \mathrm{C} /$ A)A(A/C)(A/C) (Cavener 1987), and the predicted translation product is a 400 -amino-acid protein with an approximate molecular mass of $44,000 \mathrm{kD}$. Hydropathy analysis revealed one hydrophobic region at the amino terminus of the protein that conforms to the rules that 

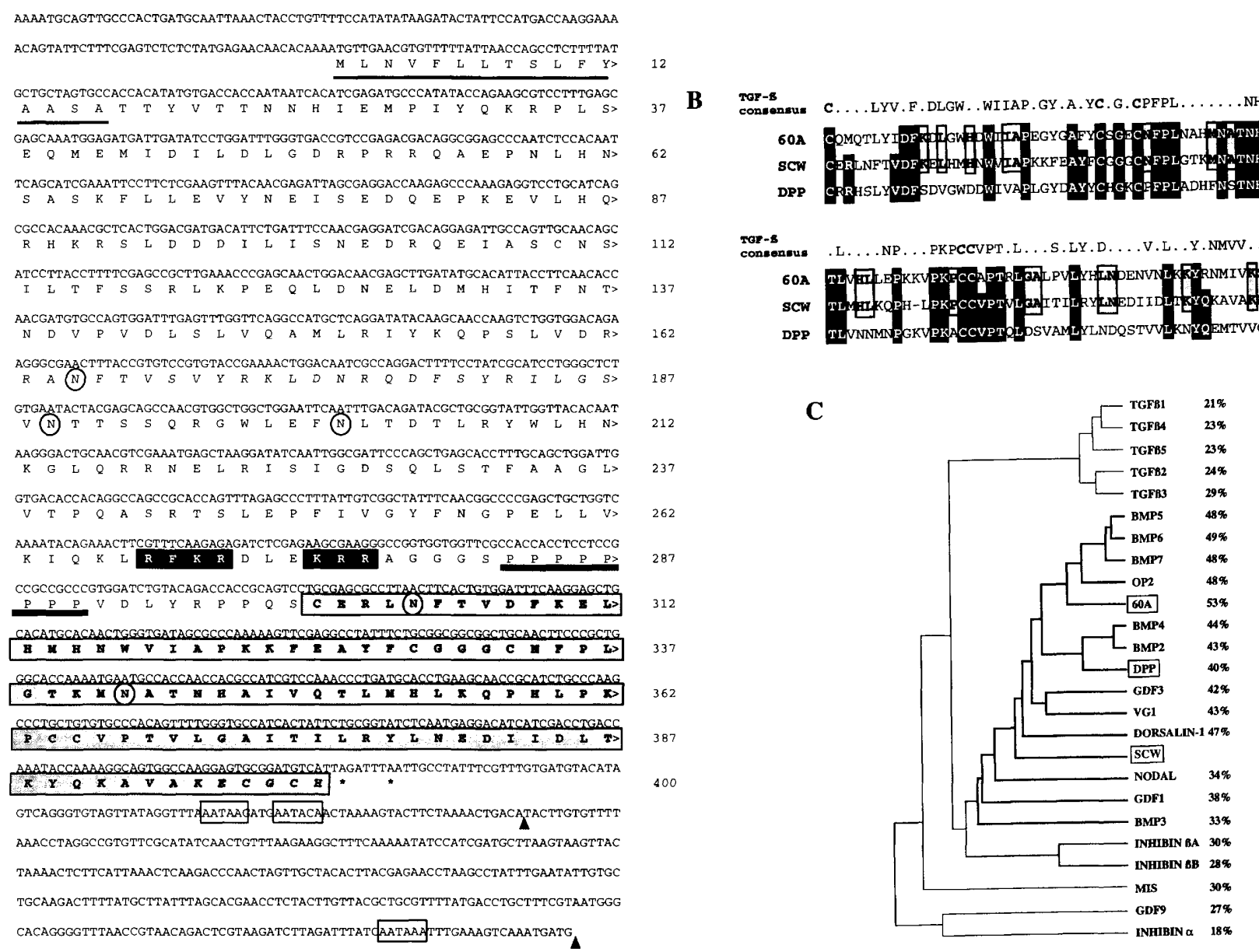

Figure 4. SCW is a member of the TGF- $\beta$ superfamily. $(A)$ Nucleotide and predicted amino acid sequence of the $s c w$ cDNA is presented. The nucleotide sequence of the 1719-bp scw CDNA contains one complete ORF, encoding a protein of 400 amino acids. The first methionine shows a good fit to the consensus Drosophila start site. Potential glycosylation sites are circled. Probable polyadenylation signals are boxed. The ends of the shorter and longer cDNA species are marked with arrowheads. The amino acid sequence at the amino terminus, underlined with a black bar, denotes a putative signal peptide. The black boxes mark basic residues that conform to probable proteolytic cleavage sites. The carboxy-terminal region showing the highest sequence conservation with members of the TGF- $\beta$ superfamily is shaded. A polyproline stretch preceding this region is marked with a shaded bar. $(B)$ Comparison of the amino acid sequence of SCW with 60A and DPP. Only the carboxy-terminal 101 amino acids of the predicted protein sequence of SCW were used in this alignment (and in the dendogram in $C$ ), starting with the first conserved Cys residue. The seven conserved Cys residues are in bold letters in the consensus sequence. Residues that are identical are boxed in black. Conserved residues between 60A and SCW, as well as between SCW and DPP, are boxed in light and dark gray, respectively. The gap introduced to optimize the alignment is represented by a dash. The alignment was generated using Gene Works (Intelli Genetics, Inc.). (C) A dendogram generated using the UPGMA algorithm (Nei 1987), illustrating the phylogenetic relationships among proteins of the TGF- $\beta$ superfamily (Massague 1990; Kingsley 1994a, and references therein). The length of the horizontal lines connecting one sequence to another is proportional to the estimated genetic distance between the sequences. Alongside each branch, the percent amino acid identity with $\mathrm{SCW}$ is denoted.

define signal sequences, suggesting that $s c w$ encodes a secreted protein (Fig. 4A; Kyte and Doolittle 1982). A probable signal peptide cleavage site can be positioned after Ala-16 (von Heijne 1985). There are five potential sites for amino-glycosylation. Two in-frame termination codons at positions 1315 and 1318 , respectively, are located at identical positions in both cDNAs, suggesting that the two transcripts differ only in their 3 '-untranslated region and use alternate polyadenylation sites.
Both cDNAs contain poly|A) addition signals 18-25 bp upstream from the start of the poly(A) tail.

scw encodes a novel member of the TGF- $\beta$ family most closely related to the bone morphogenetic proteins

A data base search using the BLAST Network Service and the translated GenBank data base (release 80, Bilof- 
sky and Burks 1988), revealed that the predicted scw protein displays extensive homology to members of the TGF- $\beta$ superfamily of secreted proteins. These include the prototypical TGF- $\beta$ molecules, members of the DPP/ Vg1/BMP family, and activins and inhibins (for review, see Kingsley 1994a). Proteins of this class are typically synthesized as inactive dimers that undergo proteolytic cleavage to generate a mature carboxy-terminal segment that forms the ligand molecule (for review, see Massagué 1990). Two other Drosophila genes that encode TGF- $\beta$ like proteins are $d p p$ and $60 \mathrm{~A}$ (Padgett et al. 1987; Wharton et al. 1991; Doctor et al. 1992). The primary structure of SCW contains all of the features characteristic of this family of proteins. The putative precursor contains an amino-terminal signal sequence and several aminolinked glycosylation sites, consistent with the idea that the $s c w$ protein is secreted (Fig. 4A). As in other TGF- $\beta$ like proteins, the conserved carboxy-terminal region is immediately preceded by a series of basic residues that could form a site for proteolytic cleavage of the precursor protein (Celeste et al. 1990; Barr 1991). In the case of SCW, two potential multibasic cleavage sites at positions 268 (RFKR) and 275 (KRR) would result in a ligand molecule with $\sim 22-28$ amino acids upstream from the first conserved Cys. One exceptional feature of the SCW protein is a string of eight Pro residues at the amino terminus of the predicted mature protein (Fig. 4A).

As is typical for members of this family, the similarity of the derived SCW sequence to other TGF- $\beta$-like proteins is highest at the carboxyl terminus. An alignment of the 101 carboxy-terminal residues of the predicted SCW protein with the Drosophila 60A and $d p p$ gene products is shown in Figure 4B. A distinguishing feature of these proteins is the presence of seven invariant Cys residues in the carboxy-terminal region of the molecule. The structure of TGF- $\beta 2$ indicates that disulfide bonds formed between these residues are important for the structure and dimerization of the protein (Daopin et al. 1992; Schlunegger and Grütter 1992). In addition to the invariant Cys residues, scw contains other conserved amino acids in the carboxyl terminus, such as the Pro residue at position 22 and the Gly at position 32 , that have been identified as critical for the correct folding and secondary structure of TGF- $\beta 2$ (Daopin et al. 1992; Schlunegger and Grütter 1992; numbering of residues as in SCW).

Members of the TGF- $\beta$ superfamily can be grouped into subfamilies with highly related sequences. The deduced evolutionary relationship indicates that SCW belongs to the DVR (Decapentaplegic-Vg related) family that includes DPP, Vgl, and the BMPs (Fig. 4C; Padgett et al. 1987; Weeks and Melton 1987; Wozney et al. 1988; Celeste et al. 1990; Lyons et al. 1991|. Overall, between $18 \%$ and $53 \%$ of the amino acid residues in the conserved active domain of SCW are identical with those in other TGF- $\beta$-like proteins. SCW shares $53 \%$ identity with $60 \mathrm{~A}$ and $40 \%$ identity with DPP, in the carboxyterminal region. Interestingly, the mammalian homologs of DPP, BMP-2, and BMP-4, are $75 \%$ identical to DPP in the mature signaling portion of the molecule
(Padgett et al. 1987; Wozney et al. 1988). In an analogous manner BMP-5, BMP- 6 , and BMP-7, which share $\sim 75 \%$ residues within the group, are $73 \%$ identical to $60 \mathrm{~A} / \mathrm{Ce}$ leste et al. 1990; Wharton et al. 1991; Doctor et al. 1992). By comparison, the greatest sequence conservation between the predicted $s c w$ protein and a vertebrate gene $(49 \%$ with BMP-6) is considerably less. The divergence between SCW and other TGF- $\beta$-like proteins suggests that $s c w$ is not an ortholog of a known vertebrate member of the TGF- $\beta$ superfamily.

The prodomain of TGF- $\beta$ proteins is usually poorly conserved across different subfamilies. However, the sequence conservation between SCW, 60A, and BMP- 6 extends into the proregion of the protein as well. SCW shares $36-39 \%$ identity in the amino-terminal region with BMP-6 and 60A, respectively (data not shown).

scw transcripts are uniformly distributed in blastoderm-stage embryos

Hybridization of digoxigenin-labeled scw probe to wildtype embryos (Tautz and Pfeifle 1989) revealed that the $s c w$ gene is ubiquitously expressed during early stages of embryogenesis but shows very tight temporal regulation (Fig. 5). Early cleavage-stage embryos contain no detectable message (Fig. 5A). Moderate levels of $s c w$ mRNA are first detected in a stage 4 embryo at $\sim 1.5 \mathrm{hr}$ of develop-

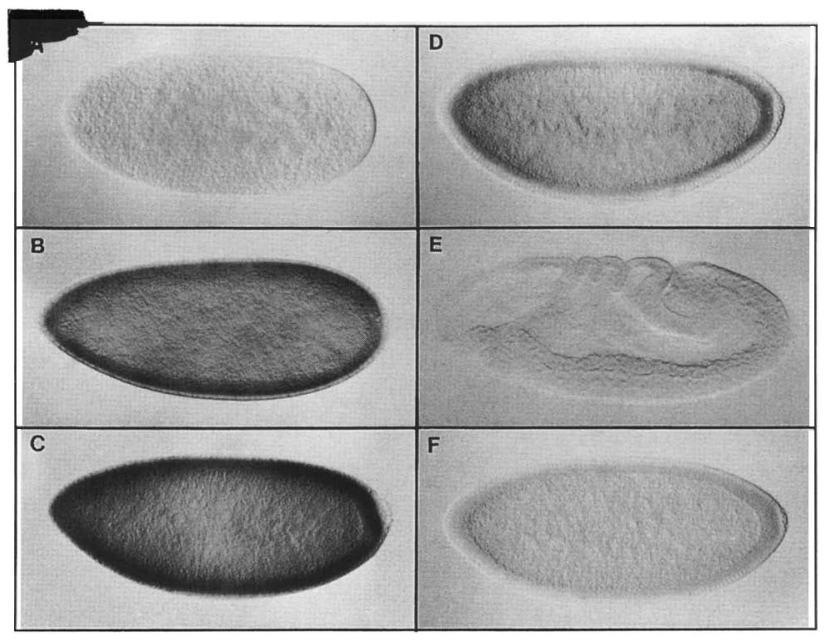

Figure 5. Spatial distribution of $s c w$ RNA during early embryogenesis. Embryos were hybridized with digoxigenin-labeled riboprobe derived from the scw-2A cDNA clone in the antisense $(A-E)$ and the sense direction $(F)$. Anterior is to the left and dorsal is up. $(A)$ Stage 2 embryo, to show the absence of maternal transcript. (B) Syncytial blastoderm embryo at stage 4 (nuclear cycle 11) shows ubiquitous expression of $s c w$ mRNA. (C) Syncytial blastoderm embryo at stage 4 (nuclear cycle 12) with very high levels of expression. There is some modulation of $s c w$ expression in the middle region of the embryo along the anterior-posterior axis. $(D)$ Cellular blastoderm embryo at stage 5, with very low levels of transcript. $(E)$ Stage 7 embryo at gastrulation; $s c w$ transcripts are below levels of detection. $(F)$ Embryo at the same stage as the embryo in $C$ hybridized with a sense riboprobe as control, reveals essentially no background staining. 
ment, toward the end of nuclear cycle 10 [data not shown; staging according to Campos-Ortega and Hartenstein (1985)]. During syncytial blastoderm, at nuclear cycle 11-12, the level of message rapidly increases /Fig. $5 \mathrm{~B}, \mathrm{Cl}$. The pole cells, the progenitors of the germ line, do not accumulate $s c w$ transcript. Levels of $s c w$ transcript then decline very rapidly to below detection in embryos at cellular blastoderm stage 5 (at $\sim 2.5 \mathrm{hr}$, Fig. 5D). During gastrulation and the rest of embryonic development, scw mRNA is below the detection threshold (Fig. 5E). Control embryos hybridized with sense riboprobe derived from the $s c w$ cDNA show no signal (Figure 5F). Thus, the $s c w$ gene is expressed during early zygotic development consistent with its mutant phenotype. However, the uniform expression of $s c w$ transcripts is curious, as the mutant phenotype suggests that $s c W$ activity is required only in dorsal cells. In this respect, scw RNA distribution differs strikingly from that of other genes involved in dorsal cell specification, that is, $d p p$, tld, and $z e n$, which are transcribed only in the dorsal half of the embryo at cellular blastoderm (Rushlow et al. 1987; St. Johnston and Gelbart 1987; Ray et al. 1991; Shimell et al. 1991).

scw expression on the dorsal side is sufficient for normal development

To test whether expression of scw in dorsal cells alone is sufficient for pattern specification, we used the tld promoter to restrict $s c w$ transcription to the dorsal side at the blastoderm stage of embryonic development. A 0.8$\mathrm{kb}$ fragment of the tld promoter is capable of directing expression in dorsal cells, in a pattern reminiscent of the endogenous tld gene (Shimell et al. 1991; Kirov et al. 1994). A P-element transformation construct containing the tld promoter fused upstream of the $1.4-\mathrm{kb} s c w$ cDNA was injected into embryos and transgenic animals were recovered (Fig. 6). The expression pattern of the tld promoter-scw fusion was assayed in embryos homozygous for the deficiency $D f(2 L) O D 16$, which do not contain any endogenous $S C W$ mRNA. Hybridization with a digoxigenin-labeled $s c w$ probe confirmed that the tld promoter was driving $s c w$ expression only in dorsal cells (Fig. 6).

Three independent P-tld/scw] transformant lines were tested for their ability to rescue severe $s c w$ alleles. In each case, homozygous scw mutants were rescued to viability and fertility, demonstrating that dorsal expression of $s c w$ is sufficient to allow the elaboration of a normal dorsal pattern. In particular, the absence of $s \mathrm{cw}$ expression on the ventral side has no developmental consequences. This result has important implications because it suggests that SCW function is restricted to dorsal regions, perhaps by its interaction with a localized component of the signaling pathway.

\section{Injected dpp RNA rescues the scw mutant phenotype}

Genetic studies have demonstrated that $s c w$ and $d p p$ mutants display similar abnormalities in embryonic pat-
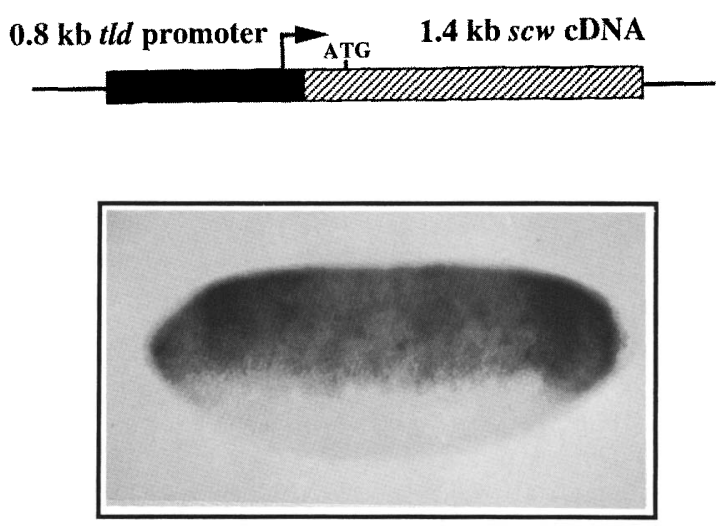

Figure 6. tld regulatory sequences restrict $s c w$ expression to dorsal cells. The tld promoter-scw construct is an $\sim 800$-bp fragment that contains the $t l d$ regulatory sequences from -728 to +68 , fused to the leader of the scw cDNA. Dorsolateral view of an embryo carrying a copy of the fusion construct and homozygous for a deficiency, $D f(2 L) O D 16$, which deletes the endogenous scw gene. The embryo was hybridized with digoxigeninlabeled riboprobe to detect $s c w$ transcript. $s c W$ transcripts are expressed in a dorsal on/ventral off pattern typical of $t$ ld expression (Shimell et al. 1991). Some expression is seen at the poles of the embryo.

tern and that both genes have a role in specifying cell fate in the dorsal part of the embryo (this work; Irish and Gelbart 1987; Wharton et al. 1993). Given the structural similarity of SCW and DPP to secreted proteins involved in inductive processes, it is plausible that both gene products act as signals to induce dorsal cells to differentiate. However, the $d p p$ mutant phenotype is more severe than the $s c w$ phenotype, suggesting a more stringent requirement for $d p p$. In addition, embryos mutant for both $s c w$ and $d p p$ do not have a stronger phenotype than $d p p$ null embryos (Arora and Nüsslein-Volhard 1992). Thus, it is possible that SCW function may be required to enhance DPP activity. Because $d p p$ expression is unaltered in SCW mutants (Ray et al. 1991), the effect of scw on DPP activity cannot be attributable to transcriptional regulation. To establish the relationship between $d p p$ and $s c w$, we determined whether injection of $d p p$ message into $s c w$ null embryos was sufficient to restore dorsal pattern.

Our results indicate that excess $d p p$ can overcome the requirement for $s \mathrm{cw}$ function (Fig. 7). In vitro-transcribed dpp mRNA was injected into $s c w$ null embryos prior to cellularization. The mutant chromosome bears a P-Krüppel ( $\mathrm{Kr}$ )-lacZ insert that marks amnioserosa cells (see Materials and methods). Uninjected mutants do not differentiate an amnioserosa and hence do not express the lacZ marker (Fig. 7B). Following injection with 75 $\mu \mathrm{g} / \mathrm{ml}$ of $d p p$ message, $60 \%$ of the $s c w$ null mutants differentiate a large number of amnioserosa cells (Fig. 7 C). An additional $22 \%$ display a fairly normal morphology of the embryo suggesting partial rescue, even though the number of amnioserosa cells in these embryos was small (data not shown). Thus, in embryos that lack SCW 


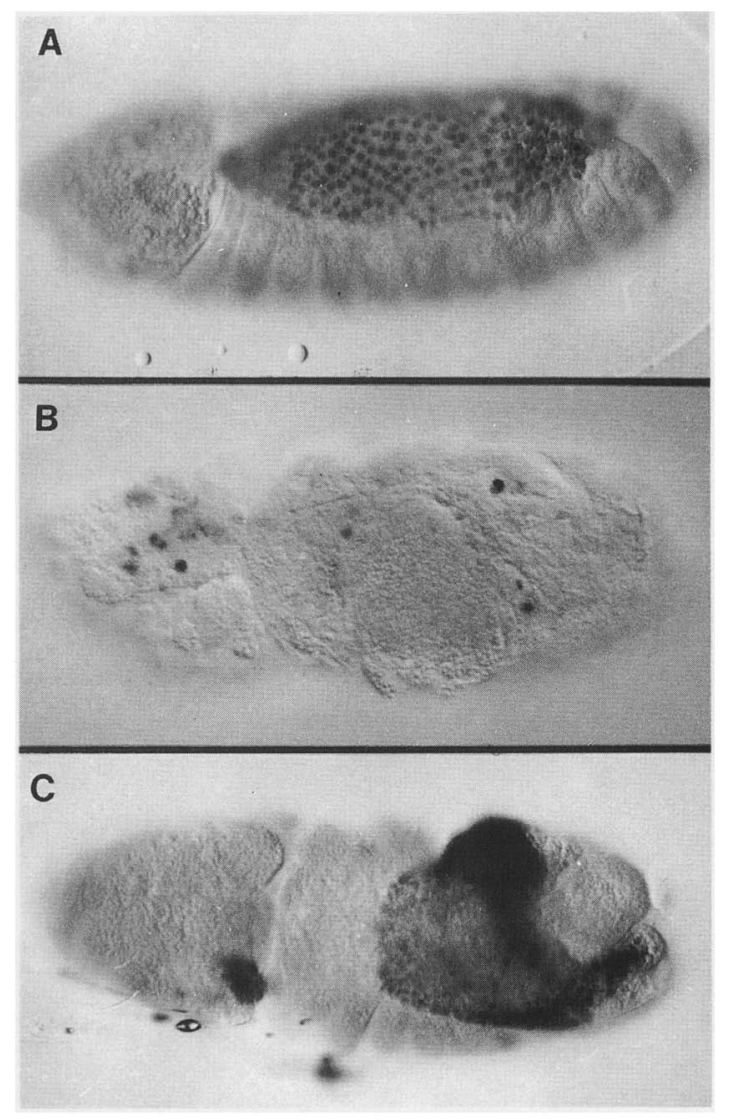

Figure 7. Response of $s c w$ mutant embryos to injected $d p p$ RNA. Injection of in vitro-transcribed $d p p$ RNA into precellular blastoderm $s c w$ embryos results in suppression of the $s c w$ mutant phenotype. The presence or absence of the dorsal most pattern element, the amnioserosa, was assayed by expression of the $\mathrm{P}(\mathrm{Kr}-\mathrm{lacZ})$ construct in which the amnioserosa element of the $K r$ upstream regulatory element drives expression of $l a c Z$. The P lac Z marker was recombined into the chromosome carrying the $s c w^{s 12}$ allele used in these experiments (see Material and methods). Expression was assayed by immunostaining with an antibody directed against lacZ. Embryos are oriented dorsal side facing the viewer, anterior to the left. $(A)$ Wild-type embryo at stage 13 showing $l a c Z$ staining almost exclusively in the amnioserosa cells. $(B) s c w^{S 12}$ embryo showing no amnioserosa cells. The few cells staining in the mutant are neuroblast precursors that are displaced in the ventralized embryo. $(C) 60 \%$ of the $s c w^{s 12}$ embryos $(n=145)$ injected with $75 \mu \mathrm{g} / \mathrm{ml}$ of $d p p$ RNA showed an expanded amnioserosa, as in the embryo shown here. A small group of injected mutant embryos $(22 \%)$ elicited a weaker response; only a small patch of stained cells resembling the amnioserosa were observed (data not shown). However, the morphology of the embryos in this group was quite normal, suggesting partial rescue. Mutant embryos were recognized by the absence of expression of a $w g-l a c Z$ marker present in the balancer chromosome (see Materials and methods|.

activity, increased levels of $d p p$ can suppress the $s c w$ mutant phenotype and restore the dorsal-most pattern element, the amnioserosa. This demonstrates two critical aspects of $s c w$ function: (1) scw does not act down- stream of $d p p$; and (2) the $d p p$ signal transduction pathway is functional in $s c w$ mutant embryos. We conclude that $s c w$ may enhance DPP activity in the embryo and that the function of both genes is required to organize pattern in the dorsal part of the embryo.

\section{Discussion}

One of the fundamental questions in developmental biology is how are cells in an embryonic field specified? It is becoming clear that there are a number of possible answers. One solution is that cell fates can be established through the graded distribution of transcription factors. For example, in Drosophila the gradients of DNA-binding proteins, bicoid and dorsal, specify the anterior-posterior and dorsal-ventral axes of the embryo, respectively (Nüsslein-Volhard 1991; St. Johnston and Nüsslein-Volhard 1992). An alternative mechanism is that cell fates are assigned through the activity gradient of a diffusible ligand. Recent work has suggested that the dorsal region of the Drosophila embryo is specified by an activity gradient of DPP, a protein that belongs to the family of transforming growth factors (Ferguson and Anderson 1992a; Wharton et al. 1993). We have cloned and characterized the scw gene, which encodes a new member of the TGF- $\beta$ family, that is also required for specification of dorsal cells. In scw mutants, the activity of DPP alone is insufficient to specify extreme dorsal cell fates. Our results suggest that the diversity of dorsal cell fates depends on the combinatorial action of two signaling factors, SCW and DPP, rather than the activity of a single ligand molecule.

\section{scw activity is required only in dorsal cells}

Phenotypic analyses indicate a requirement for $s c w$ activity in early embryonic development. In agreement with this, scw transcripts are detectable in a stage 4 embryo, $\sim 1 \mathrm{hr}$ prior to the time developmental defects become apparent in scW mutants (Arora and Nüsslein-Volhard 1992). In wild-type embryos the level of scw mRNA is sharply reduced by stage $5, \sim 50 \mathrm{~min}$ after the transcripts are first visible. Despite the tight temporal regulation of $s c w$ transcription, ectopic expression of the gene does not appear to affect patterning. In transgenic animals in which the tld promoter drives scw expression, scW transcripts are detected in the dorsal ectoderm at stages 9-11, as well as in imaginal discs and the optic lobe of the brain during larval development (Shimell et al. 1991; Nguyen et al. 1994). The misexpression at late stages does not cause any overt developmental defects in adult flies. Analysis of germ-line clones suggests that $s c w$ function is not required in the germ line (Arora and Nüsslein-Volhard 1992).

It is apparent from the scw mutant phenotype and fate mapping studies, that the loss of scw function affects dorsal cells while ventral cells develop normally. In addition, the progressive loss of amnioserosa and dorsal ectoderm in alleles of increasing severity suggests that the embryo is sensitive to reduction in the levels of the 
scw product (Figs. 1 and 2). These data indicate that despite the uniform distribution of $s c w$ transcripts, the dorsal-most cells are more sensitive to loss in scw function than dorsolateral cells.

The expression of scw RNA in ventral embryonic cells may not be essential. We have shown that expression of the scw cDNA in the dorsal half of the embryo, under a heterologous tld promoter, is sufficient to rescue scw mutants to viability. Although SCW encodes a secreted protein, by analogy with DPP and TGF- $\beta 1$, we do not expect it to diffuse extensively or be long lived. During embryonic gut development, $d p p$ expression in the mesoderm activates labial expression in the adjacent endodermal layer. This effect on labial expression is confined to the two to three cells closest to the $d p p$-expressing cells (Immergluck et al. 1990; Reuter et al. 1990). In the case of TGF- $\beta 1$, the active ligand is known to be bound by extracellular matrix components and is rapidly cleared from circulation (Coffey et al. 1987; Massagué 1990).

\section{The spatial restriction of SCW activity}

The discrepancy between the uniform distribution of $s c W$ transcript and the restricted effect of mutations in the gene suggests that functional $s c w$ protein may be localized or that it interacts with a localized component of the signal transduction pathway. The activity of SCW could be restricted by translation of $s c w$ message only in dorsal cells or by post-translational modification of SCW in a limited region of the embryo. This could occur by positive regulation of SCW activity in the dorsal half of the embryo or by negative regulation in ventral cells, as suggested for $d p p$ (Ferguson and Anderson 1992b).

On the basis of its structural similarity to other TGF- $\beta$ proteins, SCW is likely to be activated by proteolytic cleavage at the basic residues preceding the active ligand domain (see Fig. 4A; Celeste et al. 1990). tld encodes the Drosophila homolog of the vertebrate BMP-1 metalloprotease (Shimell et al. 1991) and, thus, is a candidate protein that may be involved in activation of SCW. Mammalian BMP-1 copurifies with other TGF- $\beta$-like BMPs and is thought to participate in activating the latent form of the ligand (Wozney et al. 1988). The similarity of the scw and tld mutant phenotypes suggests that both genes may affect the same event in pattern formation. Because tld transcripts are confined to the dorsal $40 \%$ of the embryo at the blastoderm stage, the restriction of SCW activity may result from its interaction with tld (Fig. 8A). Along similar lines, recent studies suggest that a key step in generating the body axis in Xenopus may be the post-translational activation of $V g 1$ in a restricted region of the embryo (Thomsen and Melton 1993). Interestingly, a tld-like gene has been identified in Xenopus as well (Maéno et al. 1993).

Another explanation for the restriction of $s c w$ function to dorsal cells may be that $s c w$ and $d p p$ act together to specify dorsal structures. $d p p$ behaves as a graded morphogen in the dorsal half of the embryo and establishes at least two cellular response thresholds: one for speci- fication of the dorsal ectoderm, and a second, higher threshold for the specification of amnioserosa (Ferguson and Anderson 1992a; Wharton et al. 1993). In scw mutants, the higher threshold for amnioserosa is not achieved and the lower threshold for establishment of dorsal epidermis is shifted to a more dorsal position with respect to wild-type embryos (see fate map in Figs. 1 and $8 \mathrm{C}$ ). Thus, the phenotypic analysis suggests that in the absence of $s c w$ function, DPP alone is unable to establish both thresholds in their normal position.

Given the structural similarity between DPP and $\mathrm{SCW}$, we suggest that $s c w$ functions as a signaling molecule by forming heterodimers with DPP (Fig. 8B). scw transcripts are expressed uniformly in early embryos, so SCW homodimers could be formed in all cells along the DV axis. Expression of $d p p$, however, is confined to the dorsal $40 \%$ of the embryo, and thus SCW/DPP heterodimers would only form in this restricted region. We propose that DPP homodimers are capable of signaling, but SCW/DPP heterodimers elicit a stronger response. In $d p p$ mutants no dorsal pattern is specified, suggesting that $\mathrm{SCW}$ homodimers alone are ineffective in specifying pattern (Fig. 8B,C). In contrast, the ability of DPP homodimers to elicit a basal response may explain why the scw mutant phenotype is less severe than that of $d p p$ (Fig. 8C). A prediction of this model is that excess quantities of DPP homodimers should be sufficient to override the requirement for the SCW/DPP heterodimer. This might explain why injections of $d p p$ message are capable of rescuing the scw mutant phenotype. Thus, in wild-type embryos, the activity gradient that specifies dorsal pattern may be composed of both SCW/DPP heterodimers and DPP homodimers (Fig. 8C). The greater potency of SCW/DPP heterodimers compared with the DPP homodimers could result from a higher affinity of the heterodimer for a common set of receptors. The recent identification of BMP receptors in Drosophila, that may bind SCW and DPP with different affinities could allow us to test this model (Brummel et al. 1994; Nellen et al. 1994; Penton et al. 1994). The interaction of SCW with DPP might also be the basis for the graded nature of the $s c w$ mutant phenotype. In a multicomponent gradient system, the loss of any element that affects the efficacy of the system will produce a graded effect, even if the lost component is not graded.

An example of how the composition of a TGF- $\beta$-like molecule can drastically alter its activity is provided by the inhibins and activins, which share common subunits. Activins that are made up of $\beta$ subunits have the opposite biological activity to the inhibins, which consist of both $\alpha$ and $\beta$ subunits, demonstrating the diversity of function that can be obtained from a combination of ligand subunits (Yu et al. 1987; Petraglia et al. 1989). TGF- $\beta 1 / 2$, TGF- $\beta 2 / 3$ and some of the BMPs (BMP-3, BMP-6, and BMP-7) have been shown to form heterodimers (Cheifetz et al. 1987; Massagué 1990, 1992; Ogawa et al. 1992, and references therein). Similarly, functional bovine osteogenic protein is composed of heterodimers of OP-1 and BMP-2 (Sampath et al. 1990).

The genetic interaction observed between certain $s c W$ 
A. TLD may modify SCW in dorsal cells

d

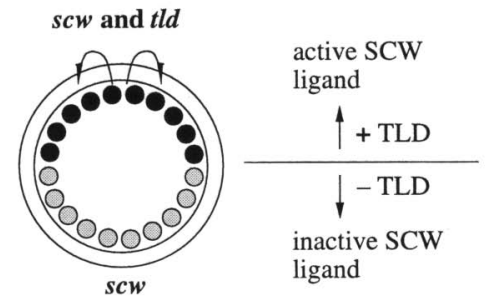

$\mathbf{v}$
B. DPP may form active heterodimers with SCW in dorsal cells

d

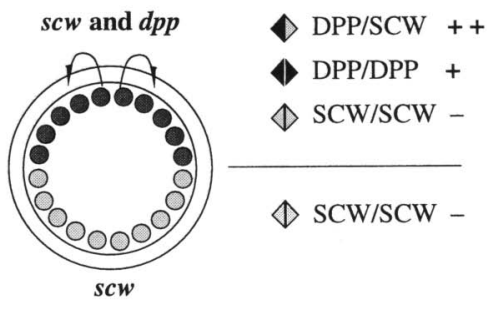

C. SCW and DPP specify pattern combinatorially
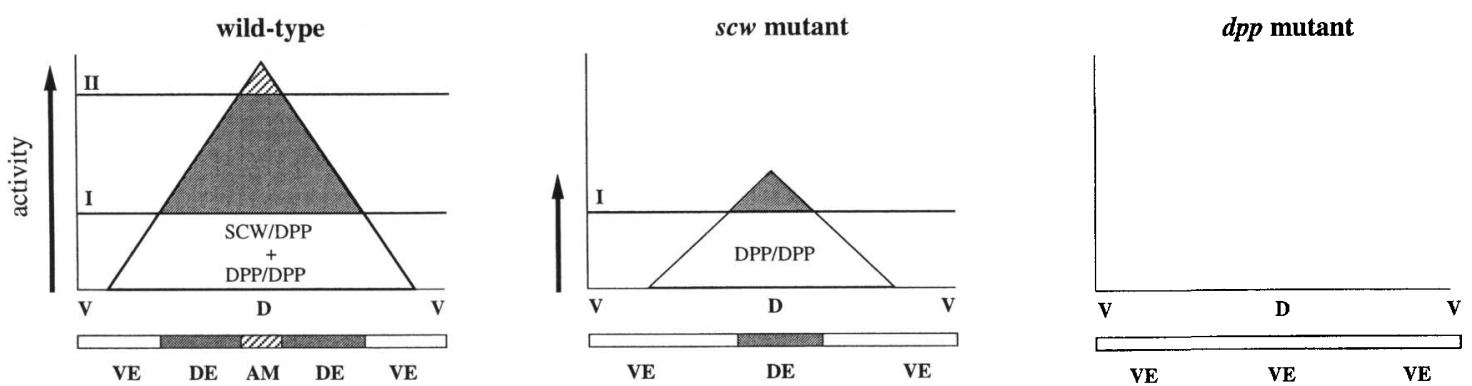

Figure 8. Model of $s c w$ gene function in the specification of dorsal pattern. $A$ and $B$ outline two mechanisms by which $s c w$ activity may be localized to dorsal cells. Diagrams represent cross sections through an embryo at cellular blastoderm stage with the dorsal (d) and ventral $|\mathrm{v}\rangle$ sides indicated. The outer circle represents the vitelline membrane that surrounds the inner embryonic membrane. The arrows depict secretion of gene products into the fluid-filled extracellular perivitelline space. The small circles represent nuclei. $(A)$ The $s c w$ gene is transcribed in all nuclei, whereas only dorsal nuclei (solid circles) express tld. The restricted expression of $t l d$ leads to the formation of active SCW ligand only in the dorsal half of the embryo. $(B)$ Nuclei on the dorsal side express both $s c W$ and $d p p$ (solid circles), whereas ventral nuclei (shaded circles) express only scw. We propose that DPP homodimers and DPP/SCW heterodimers, which are active in signaling, are formed only on the dorsal side. SCW homodimers, which are inactive, are formed on both dorsal and ventral sides. $(C)$ Schematic representation of the activity gradient that defines pattern in the dorsal half of the embryo. The vertical axis represents the height of the gradient with its high point in the dorsal-most cells. The positions marked represent the activity thresholds necessary for the specification of dorsal ectoderm (I) and the amnioserosa (II). The horizontal axis depicts the tissue types differentiated in response to the signaling activity and their position along the DV axis. (AM) Amnioserosa; (DE) dorsal ectoderm; (VE) ventral ectoderm. In the wild-type embryo SCW/DPP heterodimers and DPP homodimers contribute to the activity gradient. The mechanism by which the activity gradient is established is not completely understood. In the scw mutants only DPP homodimers are formed and only the lower threshold is achieved. Thus, dorsal ectoderm is shifted dorsally, instead of at its normal dorsolateral position. In a dpp mutant neither DPP homodimers nor DPP/SCW heterodimers are formed, resulting in the total absence of signaling activity; therefore, all dorsal cells develop as ventral ectoderm.

and $d p p$ alleles is consistent with a possible physical association of the proteins encoded by these genes. Specific alleles of scw have been identified that fail to complement a recessive, partial loss-of-function $d p p$ allele (Raftery et al. 1994). Embryos carrying a single copy of both mutations (trans-heterozygotes) die with a partially ventralized phenotype. In contrast, embryos carrying a deficiency for the $s c w$ locus and the same allele of $d p p$ are completely viable, indicating that the defective product encoded by the gain-of-function $s c w$ allele can block the activity of the remaining functional copy of $d p p$. The gain-of-function alleles of $s c w$ may be incapable of signal transduction but still sequester active $d p p$ molecules and thus reduce the effective levels of $d p p$ in the embryo.
The haplo-insufficiency of the $d p p$ locus reflects the sensitivity of the embryo to reduction in levels of $d p p$ activity (Irish and Gelbart 1987; Ferguson and Anderson 1992a; Wharton et al. 1993). If $s c w$ and $d p p$ act together, it might be expected that the $s c w$ locus would also be haplo-insufficient. However, embryos with a single functional copy of $s c w$ are viable. An explanation may be that only $d p p$ is limiting in the embryo while $s c w$ is present in excess.

Multiple TGF- $\beta$ signaling molecules in development: implications for function

Several members of the TGF- $\beta$ superfamily of secreted 
proteins are involved in key developmental events in vertebrate and invertebrate systems (Lyons et al. 1991; Kingsley 1994a). An emerging theme is that many of these molecules act combinatorially to specify cell fate. For example, in Xenopus embryos the dosage-dependent induction of dorsal mesoderm by activin can be potentiated by the addition of other factors such as basic-fibroblast growth factor (b-FGF). It has been suggested that activin and FGF may act synergistically to specify the mesoderm (Kimelman and Kirschner 1987; Green and Smith 1990; Kimelman et al. 19921.

The BMPs are an example of a group of structurally related proteins that function in a common pathway of tissue differentiation. Although initially identified as a copurifying mixture of proteins, several of the BMPs are capable of inducing de novo bone formation individually (Wozney 1992; Kingsley 1994b, and references therein). Given this result, the functional significance of the existence of multiple BMPs is not clear. The overlapping spatial expression of several BMPs in murine embryos has led to the suggestion that these genes may combinatorially regulate aspects of vertebrate development (Lyons et al. 1990; Jones et al. 1991). In mice, the short ear (BMP-5) and brachypodism (GDF-5) mutations cause very specific defects in skeletal development, despite the broad expression of these genes in other regions of the embryo (Kingsley et al. 1992; Storm et al. 1994). It is possible that the regions affected are those in which a particular BMP is uniquely required and active. Alternatively, broad regions of the embryo may be specified by basal levels of a BMP signaling pathway, whereas limited regions may require a higher threshold of activity that is only provided by a combination of ligand molecules. Our data strongly support the latter alternative. Mutations in $d p p$ have a severe effect on development, suggesting that it is the basal signal for dorsal patterning in the Drosophila embryo. In contrast, despite its uniform expression, the effects of mutations in $s c w$ are restricted to the region of overlap with $d p p$ expression. These results may be of general relevance in view of the striking structural and functional conservation between the genes that specify dorsal pattern in Drosophila and the homologous genes required for osteogenesis in vertebrates (Padgett et al. 1993; Sampath et al. 1993).

We have demonstrated that the specification of dorsal pattern in the Drosophila embryo requires at least two TGF- $\beta$-like signaling molecule, SCW and DPP. Our results indicate that both proteins must be present to achieve the levels of activity required to specify the entire range of patterns that derive from dorsal embryonic cells. The interactions between SCW and DPP, two structurally related TGF- $\beta$-like proteins that have a common function and overlapping domains of expression, could provide a conceptual frame work for understanding related processes in vertebrates.

\section{Materials and methods}

Drosophila stocks

The X-ray induced deficiency $D f(2 L) s c w / E 1 r 2]$ was isolated and genetically characterized by V. Twombly and L. Raftery (Raftery et al. 1994). The $d p p^{H 48} / \operatorname{In}(2 L R) C y O, P 23$ stock was provided by W. Gelbart (Harvard University, Cambridge, MA). For RNA injection experiments, embryos were obtained from a stock carrying the $s c w^{s 12}$ allele as well as a P-Kr-lacZ insert recombined onto the same chromosome. The line was maintained over a $\mathrm{CyO}$ balancer carrying a $\mathrm{P}-\mathrm{lacZ}$ insert in the wingless (wg) gene. Homozygous $s C w$ embryos were unambiguously identified by the absence of $w g-l a c Z$ expression. Flies carrying the P-lacZ inserts used to construct the injection stock were obtained from G. Struhl (Columbia University, NY) and S. Cohen (EMBL, Heidelberg, Germany).

Cuticle preparations were performed as described in Wieschaus and Nüsslein-Volhard (1986). A description of the other mutants and the balancer chromosomes used can be found in Lindsley and Zimm (1992) and Arora and Nüsslein-Volhard (1992). Fly stocks were obtained from the Bloomington Stock Center, Indiana.

\section{Cloning of scw, isolation of $\mathrm{CDNA}$, and sequencing}

Genomic DNA clones corresponding to $\lambda \mathrm{E} 86$, a brain specific homeobox-containing clone that maps to the $38 \mathrm{~A}$ region (Jones and McGinnis 1993), were isolated from a Canton-S $\lambda$ EMBL 4 library provided by A. Preiss (Biozentrum, Basel, Switzerland). These clones were used as the starting point for a genomic walk spanning much of the $38 \mathrm{Al}, 2$ subdivisions. Standard protocols for library screening, Southern hybridization, and phage purification were employed (Sambrook et al. 1989).

For the reverse Northern blot, poly $(\mathrm{A})^{+}$RNA extracted from 2- to 6-hr embryos was used in reverse transcription reactions primed with random hexanucleotides and hybridized to Southern blots of genomic clones corresponding to the $50-\mathrm{kb}$ region between the distal breakpoint of $D f(2 L) O D 16$ and the proximal breakpoint of $D f(2 L) s c w[E 1 r 2]$. Two cDNA libraries, a 0- to 4-hr embryonic library (Brown and Kafatos 1988) and a commercially available 2- to 4-hr embryonic library (Novagen, Inc.), were screened with DNA from the 50-kb minimal genomic region. The longest cDNA corresponding to each separate transcription unit was used as a probe in Southern blots to generate the data presented in Figure 3A.

Clone scw-2A is a full-length cDNA isolated from the 0- to 4-hr library, and the clone scw- $\mathrm{N}$ was isolated from the 2- to 4-hr library. The sequence of cDNA isolates, $2 \mathrm{a}$ and $\mathrm{N}$, was determined on both strands by the dideoxy chain termination method (Sanger et al. 1977), using Sequenase version 2.0 (U.S. Biochemical).

\section{Plasmids and constructs}

For genomic rescue constructs, the $12.6-\mathrm{kb}$ SalI fragment (pKA45), the 11.7-kb BamHI fragment (pKA55), and the $\sim 12-\mathrm{kb}$ BamHI fragment (pKA66; Fig. 3A) were subcloned into the pCaSpeR vector (Pirrotta 1988). Construct pKA45 includes the 1.4-kb cDNA as well as an additional $6 \mathrm{~kb}$ of $5^{\prime}$ and $5 \mathrm{~kb}$ of 3 '-flanking sequences. The construct pKA55 also contains the 1.4-kb cDNA but has only $2 \mathrm{~kb}$ of 5 '-flanking sequences. Construct pKA66 contained the $3.0-\mathrm{kb}$ cDNA. The dlar cDNA containing the entire coding region $(7.4-\mathrm{kb})$ was subcloned into $\mathrm{pCaSpeR}-h s p 83$ and $\mathrm{pCaSpeR}-h s p 70$ vectors for transformation rescue constructs. The 900 -bp BamHI-RsaI fragment of the $h s p 83$ promoter in $\mathrm{pCaSpeR}$ drives constitutive expression in the embryo (Zimmerman et al. 1983; Govind et al. 1993). The hsp 70 promoter is heat shock inducible (Pirrotta 1988). The full-length dlar cDNA was the gift of $\mathbf{H}$. Saito (Dana-Farber Cancer Center, Boston, MA). For the $t l d$ promoter-scw fusion 
construct, the entire coding region was isolated as a HindIIINotI fragment from the $s c w$ cDNA clone $2 \mathrm{~A}$ in pNB40 and inserted downstream of the 796-bp BamHI-KpnI fragment containing the tld regulatory sequences (Kirov et al. 1994) in pCaSpeR.

\section{P-element transformation and rescue}

A homozygous $D f(1) w, y w^{67 c 23}$ stock was used as a recipient for germ-line transformation (Rubin and Spradling 1982). For transformation rescue experiments, homozygous viable transformant lines that carried an insert in the third chromosome were used. Male flies of the genotype $s c w^{s 12} / \mathrm{CyO}$; P-transgene/TM3 were crossed to females $s c W^{I G 76} / \mathrm{CyO}$; P-transgene/TM3, or $D f(2 L) O D 16 / C y O ;$ P-transgene/TM3. The progeny from this cross were scored for the survival of $s c w^{s 12} / s c w^{I G 76}$ or $s c w^{512}$ / $D f(2 L) O D 16$ offspring. In the cases where rescue was observed, survival was $60-90 \%$ of that expected. Expected survival was calculated as half the total number of $\mathrm{CyO}$ flies hatching from an individual cross. Control crosses lacking any transformant resulted in $0 \%$ survival of $s c w^{s 12} / s c w^{I G 76}$ or $s c w^{S 12} / D f(2 L)$ OD16 progeny.

\section{Analysis of scw RNA expression}

For the Northern blot, total RNA was isolated from staged embryos, larvae, and adults by the hot phenol method (Jowett 1986). Poly(A) ${ }^{+}$RNA was purified using the Poly A Tract mRNA Isolation System (Promega). Approximately $5 \mu \mathrm{g}$ of RNA was loaded per lane. Hybridization with random primed probes was carried out according to the conditions of Church and Gilbert (1984).

Embryos were fixed for in situ hybridization as described by Tautz and Pfeifle (1989). Hybridization and detection were carried out using standard conditions with the modification that hybridization temperature was $55^{\circ} \mathrm{C}$. Sense and antisense $s c w$ probes, derived from the $1.4-\mathrm{kb}$ scw-2A cDNA in pBluescript II (Stratagene), were labeled with digoxigenin-UTP (Boehringer Mannheim|.

\section{RNA injections and antibody labeling}

The complete $d p p$ cDNA sequence, isolated as a 2.7-kb EcoRI fragment from plasmid E55 (Padgett et al. 1987), was inserted into pBluescript II. For scW RNA, the plasmid used for in situ localization was used (see above). Linearized plasmids were transcribed to generate capped RNA transcript in the sense orientation, according to Sambrook et al. (1989). After digestion with DNase, the RNA was ethanol precipitated and the concentration determined spectrophotometrically. RNA transcripts were injected into precellular blastoderm embryos at the posterior pole. Embryos were aged until stage 13 prior to assaying expression. Expression of $\mathrm{Kr}$ and/or lacZ in injected embryos was assayed using polyclonal antibodies (Ferguson and Anderson 1992a). Antibody directed against the $K r$ protein was provided by R. Warrior (University of Southern California, Los Angeles) and C. Rushlow (Roche Institute, Nutley, NJ), and a commercially available $l a c Z$ antibody was used (Promega).

\section{Acknowledgments}

We thank Bill Gelbart, Vern Twombly, Laurel Raftery, Haruo Saito, and Neil Krueger for sharing information and fly stocks prior to publication. The $b s h$ clone provided by Brad Jones and Bill McGinnis was the starting material for the $s c w$ walk. Special acknowledgement goes to Chris Rushlow, Rahul Warrior, and Mary Jane Shimell for advice and discussions and to Larry Marsh, Dan Woods, and Guillermo Marqués for helpful comments on the manuscript. We thank Thao Nguyen and Hien Tran for excellent support. This work was supported by U.S. Public Health Service grants GM-47462 and GM-00599 from the National Institutes of Health to M. O'Connor.

The publication costs of this article were defrayed in part by payment of page charges. This article must therefore be hereby marked "advertisement" in accordance with 18 USC section 1734 solely to indicate this fact.

\section{Note added in proof}

The sequence data described in this paper have been deposited to the EMBL/GenBank data libraries.

\section{References}

Arora, K. and C. Nüsslein-Volhard. 1992. Altered mitotic domains reveal fate map changes in Drosophila embryos mutant for zygotic dorsoventral patterning genes. Development 114: 1003-1024.

Barr, P.J. 1991. Mammalian subtilisins: The long-sought dibasic processing endoproteases. Cell 66: 1-3.

Bilofsky, H.S. and C. Burks. 1988. The GenBank (R) Genetic Sequence Data Bank. Nucleic Acids Res. 16: 1861-1864.

Brown, N.H. and F.C. Kafatos. 1988. Functional cDNA libraries from Drosophila embryos. J. Mol. Biol. 203: 425-437.

Brummel, T.J., V. Twombly, G. Marqués, J.L. Wrana, S.J. Newfeld, L. Attisano, J. Massagué, M. B. O'Connor, and W.M. Gelbart. 1994. Characterization and relationship of DPP/BMP receptors encoded by the Drosophila saxophone and thick veins genes. Cell 78: 251-261.

Campos-Ortega, J.A. and V. Hartenstein. 1985. The embryonic development of Drosophila melanogaster. Springer-Verlag, Berlin, Germany.

Cavener, D.R. 1987. Comparison of the consensus sequences flanking translation start sites in Drosophila and vertebrates. Nucleic Acids Res. 15: 1353-1361.

Celeste, A.J., J.A. Iannazzi, R.C. Taylor, R.M. Hewick, V. Rosen, E.A. Wang, and J.M. Wozney. 1990. Identification of transforming growth factor beta family members present in boneinductive protein purified from bovine bone. Proc. Natl. Acad. Sci. 87: 9843-9847.

Cheifetz, S., J.A. Weatherbee, M.L.S. Tsang, J.K. Anderson, J.E. Mole, R. Lucas, and J. Massagué. 1987. The transforming growth factor- $\beta$ system, a complex pattern of cross-reactive ligands and receptors. Cell 48: 409-415.

Church, G.M. and W. Gilbert. 1984. Genomic sequencing. Proc. Natl. Acad. Sci. 81: 1991-1995.

Coffey, R.J., L.J. Kost, R.M. Lyons, H.L. Moses, and N.F. La Russo. 1987. Hepatic processing of transforming growth factor $\beta$ in rat. $J$. Clin. Invest. 80: $750-757$.

Daopin, S., K.A. Piez, Y. Ogawa, and D.R. Davies. 1992. Crystal structure of transforming growth factor- $\beta 2$ : An unusual fold for the superfamily. Science 257: 369-373.

Doctor, J.S., P.D. Jackson, K.E. Raksha, M. Visalli, and F.M. Hoffmann. 1992. Sequence, biochemical characterization, and developmental expression of a new member of the TGF- $\beta$ superfamily in Drosophila melanogaster. Dev. Biol. 151: 491-505.

Ferguson, E.L. and K.V. Anderson. 1992a. Decapentaplegic acts as a morphogen to organize dorsal-ventral pattern in the Drosophila embryo. Cell 71: 451-461.

1992b. Localized, enhancement and repression of the 
activity of the TGF- $\beta$ family member, decapentaplegic, is necessary for dorsal-ventral pattern formation in the Drosophila embryo. Development 114: 583-597.

Govind, S., L. Brennan, and R. Steward. 1993. Homeostatic balance between dorsal and cactus proteins in the Drosophila embryo. Development 117: 135-148.

Green, J.B.A. and J.C. Smith. 1990. Graded changes in dose of a Xenopus activin A homologue elicits stepwise transitions in embryonic cell fate. Nature 347: 391-394.

Immergluck, K., P.A. Lawrence, and M. Bienz. 1990. Induction across germ layers in Drosophila mediated by a genetic cascade. Cell 62: 261-268.

Irish, V.F. and W.M. Gelbart. 1987. The decapentaplegic gene is required for dorsal-ventral patterning of the Drosophila embryo. Genes \& Dev. 1: 868-879.

Jones, B. and W. McGinnis. 1993. A new Drosophila homeobox gene, $b s h$, is expressed in a subset of brain cells during embryogenesis. Development 117: 793-806.

Jones, M.C., K.M. Lyons, and B.L.M. Hogan. 1991. Involvement of Bone Morphogenetic Protein-4 (BMP-4) and Vgr-1 in morphogenesis and neurogenesis in the mouse. Development 111: $531-542$.

Jowett, T. 1986. Preparation of nucleic acids. In Drosophila: $A$ practical approach (ed. D.B. Roberts), pp. 275-286. IRL Press, Oxford, UK.

Jürgens, G. 1987. Segmental organization of the tail region in the embryo of Drosophila melanogaster. A blastoderm fate map of the cuticle structures of the larval tail region. Wilhelm Roux's Arch. Dev. Biol. 196: 141-157.

Jürgens, G., E. Wieschaus, C. Nüsslein-Volhard, and H. Kluding. 1984. Mutations affecting the pattern of the larval cuticle in Drosophila melanogaster. II. Zygotic loci on the third chromosome. Wilhelm Roux's Arch. Dev. Biol. 193: 283-295.

Jürgens, G., R. Lehmann, M. Schardin, and C. Nüsslein-Volhard. 1986. Segmental organization of the head in the embryo of Drosophila melanogaster. A blastoderm fate map of the cuticle structures of the larval head. Wilhelm Roux's Arch. Dev. Biol. 195: 359-377.

Kimelman, D. and M. Kirschner. 1987. Synergistic induction of mesoderm by FGF and TGF $\beta$ and the identification of an mRNA coding for FGF in the early Xenopus embryo. Cell 51: 369-377.

Kimelman, D., J.L. Christian, and R.T. Moon. 1992. Synergistic principles of development: Overlapping patterning systems in Xenopus mesoderm induction. Development 116: 1-9.

Kingsley, D.M. 1994a. The TGF- $\beta$ superfamily: New members, new receptors, and new genetic tests of function in different organisms. Genes \& Dev. 8: 133-146.

- 1994b. What do BMPs do in mammals? Clues from the mouse short ear mutation. Trends Genet. 10: 16-21.

Kingsley, D.M., A.E. Bland, J.M. Grubber, P.C. Marker, L.B. Russell, N.G. Copeland, and N.A. Jenkins. 1992. The mouse short ear skeletal morphogenesis locus is associated with defects in a bone morphogenetic member of the TGF- $\beta$ superfamily. Cell 71: 399-410.

Kirov, N., S. Childs, S., M.B. O'Connor, and C. Rushlow. 1994. The Drosophila dorsal morphogen represses the tolloid gene by interacting with a silencer element. Mol. Cell. Biol. 14: 713-722.

Kyte, J. and R.F. Doolittle. 1982. A simple method for displaying the hydropathic character of a protein. J. Mol. Biol. 157: 105132.

Lindsley, D.L. and G.M. Zimm. 1992. The genome of Drosophila melanogaster. Academic Press, San Diego, CA.

Lohs-Schardin, M., C. Cremer, and C. Nüsslein-Volhard. 1979. A fate map for the larval epidermis of Drosophila melano- gaster: Localized cuticle defects following irradiation of the blastoderm with an ultraviolet laser microbeam. Dev. Biol. 73: 239-255.

Lyons, K.M., R.W. Pelton, and B.L.M. Hogan. 1990. Organogenesis and pattern formation in the mouse: RNA distribution patterns suggest a role for Bone Morphogenetic Protein-2A (BMP-2A). Development 109: 833-844.

Lyons, K M., C.M. Jones, and B.L.M. Hogan. 1991. The DVR gene family in embryonic development. Trends Genet. 7: 408-412.

Maéno, M., Y. Xue, T.I. Wood, R.C. Ong, and H.F. Kung. 1993. Cloning and expression of cDNA encoding Xenopus laevis bone morphogenetic protein-1 during early embryonic development. Gene 134: 257-261.

Massagué, J. 1990. The transforming growth factor- $\beta$ family. Annu. Rev. Cell Biol. 6: 597-641.

- 1992. Receptors for the TGF- $\beta$ family. Cell 69: 10671070.

Nei, M. 1987. In Molecular evolutionary genetics, pp. 293-298. Columbia University Press, New York.

Nellen, D., M. Affolter, and K. Basler. 1994. Receptor serine/ threonine kinases implicated in the control of Drosophila body pattern by decapentaplegic. Cell 78: 225-237.

Nguyen, T., J. Jamal, M.J. Shimell, K. Arora, and M.B. O'Connor. 1994. Characterization of tolloid related-1: A BMP-1 product that is required during larval and pupal stages of Drosophila development. Dev. Biol. (in press).

Nüsslein-Volhard, C. 1991. Determination of the embryonic axes of Drosophila. Development (Supp.) 1: 1-10.

Nüsslein-Volhard, C., E. Wieschaus, and H. Kluding. 1984. Mutations affecting the pattern of the larval cuticle in Drosophila melanogaster. I. Zygotic loci on the second chromosome. Wilhelm Roux's Arch. Dev. Biol. 183: 267-282.

Ogawa, Y., D.K. Schmidt, R.M. Nathan, R.M. Armstrong, K.L. Miller, S.J. Sawamura, J.M. Ziman, K.L. Erickson, E.R. de Leon, and D.M. Rosen. 1992. Bovine bone activin enhances bone morphogenetic protein induced ectopic bone formation. J. Biol. Chem. 267: 2325-2328.

Padgett, R.W., R.D. St. Johnston, and W.M. Gelbart. 1987. A transcript from a Drosophila pattern gene predicts a protein homologous to the transforming growth factor- $\beta$ family. $\mathrm{Na}$ ture 325: 81-84.

Padgett, R.W., J.M. Wozney, and W.M. Gelbart. 1993. Human BMP sequences can confer normal dorsal-ventral patterning in the Drosophila embryo. Proc. Natl. Acad. Sci. 90: 29052909.

Penton, A., Y. Chen, K. Staehling-Hampton, J.L. Wrana, L. Attisano, J. Szidonya, A. Cassill, J. Massagué, and F.M. Hoffmann. 1994. Identification of two bone morphogenetic protein type I receptors, Brk25D and Brk43E, in Drosophila and evidence that Brk25D is a functional receptor for decapentaplegic. Cell 78: 239-250.

Petraglia, F., J. Vaughan, and W. Vale. 1989. Inhibin and activin modulate the release of gonadotropin-releasing hormone, human chorionic gonadotropin, and progesterone from cultured human placenta cells. Proc. Natl. Acad. Sci. 86: 51145117.

Pirrotta, V. 1988. Vectors for P element transformation in Drosophila. In Vectors: A survey of molecular cloning vectors and their uses (eds. R.L. Rodriguez and D.T. Denhart), pp. 437-466. Butterworths, London, UK.

Raftery, L.A., V. Twombly, K. Wharton, and W.M. Gelbart. 1994. Genetic screens to identify elements of the decapentaplegic signaling pathway in Drosophila. Genetics (in press).

Ray, R.P., K. Arora, C. Nüsslein-Volhard, and W.M. Gelbart. 
1991. The control of cell fate along the dorsal-ventral axis of the Drosophila embryo. Development 113: 35-54.

Reuter, R., G.E. Panganiban, F.M. Hoffmann, and M.P. Scott. 1990. Homeotic genes regulate the spatial expression of putative growth factors in the visceral mesoderm of Drosophila embryos. Development 110: 1031-1040.

Rubin, G.M. and A.C. Spradling. 1982. Genetic transformation of Drosophila with transposable elements vectors. Science 218: 348-353.

Rushlow, C. and M. Levine. 1990. Role of the zerknüllt gene in dorsal-ventral pattern formation in Drosophila. Adv. Genet. 27: 277-307.

Rushlow, C., M. Frasch, H. Doyle, and M. Levine. 1987. Maternal regulation of zerknüllt: A homeobox gene controlling differentiation of dorsal tissues in Drosophila. Nature 330: 583-586.

Saito, H. and M. Streuli. 1991. Molecular characterization of protein tyrosine phosphatases. Cell Growth Differ. 2: 59-65.

Sambrook, J., E.F. Fritsch, and T. Maniatis. 1989. Molecular cloning: A laboratory manual, 2nd ed. Cold Spring Harbor Laboratory Press, Cold Spring Harbor, New York.

Sampath, T.K., J.E. Coughlin, R.M. Whetstone, D. Banach, C. Corbett, R.J. Ridge, E. Özkayanak, H. Oppermann, and D. Reuger. 1990. Bovine osteogenic protein is composed of dimers of OP-1 and BMP-2A, two members of the transforming growth factor- $\beta$ family. J. Biol. Chem. 265: 13198-13205.

Sampath, T.K., K.E. Rashka, J.S. Doctor, R.F. Tucker, and F.M. Hoffmann. 1993. Drosophila TGF- $\beta$ superfamily proteins induce endochondrial bone formation in mammals. Proc. Natl. Acad. Sci. 90: 6004-6008.

Sanger, F., S. Nicklen, and A.R. Coulson. 1977. DNA sequencing with chain terminating inhibitors. Proc. Natl. Acad. Sci. 74: 5463-5467.

Schlunegger, M.P. and M.G. Grütter. 1992. An unusual feature revealed by the crystal structure at $2.2 \AA$ resolution of human transforming growth factor- $\beta 2$. Nature 358: $430-434$.

Shimell, M.J., E.L. Ferguson, S.R. Childs, and M.B. O'Connor. 1991. The Drosophila dorsal-ventral patterning gene tolloid is related to human bone morphogenetic protein 1 . Cell 67: 469-481.

Sive, H.L. 1993. The frog prince-ss: A molecular formula for dorsoventral patterning in Xenopus. Genes \& Dev. 7: 1-12.

St. Johnston, R.D. and W.M. Gelbart. 1987. Decapentaplegic transcripts are localized along the dorsal-ventral axis of the Drosophila embryo. EMBO J. 6: 2785-2791.

St. Johnston, R.D. and C. Nüsslein-Volhard. 1992. The origin of pattern and polarity in the Drosophila embryo. Cell 68: 201219.

Storm, E.E., T.V. Huyunh, N.G. Copeland, N.A. Jenkins, D.M. Kingsley, and S. Lee. 1994. Limb alterations in brachypodism mice due to mutations in a new member of the TGF- $\beta$ superfamily. Nature 368: 639-643.

Streuli, M., N.X. Krueger, A.Y.M. Tsai, and H. Saito. 1989. A family of receptor-linked protein tyrosine phosphatases in humans and Drosophila. Proc. Natl. Acad. Sci. 86: 86988702.

Tautz, D. and C. Pfeifle. 1989. A non-radioactive in situ hybridization method for the localization of specific RNAs in Drosophila embryos reveals translational control of the segmentation gene hunchback. Chromosoma 98: 81-85.

Thomsen, G.H. and D.A. Melton. 1993. Processed Vg1 Protein is an axial mesoderm inducer in Xenopus. Cell 74: 433-441.

von Heijne, G. 1985. Signal sequences: The limit of variation. $I$. Mol. Biol. 184: 99-105.

Wakimoto, B.T., F.R. Turner, and T.C. Kaufman. 1984. Defects in embryogenesis in mutants associated with the Antenna- pedia gene complex of Drosophila melanogaster. Dev. Biol. 102: $147-172$.

Weeks, D.L. and D.A. Melton. 1987. A maternal mRNA localized to the vegetal hemisphere in Xenopus eggs codes for a growth factor related to TGF- $\beta$. Cell 51: 861-867.

Wharton, K.A., G.H. Thomsen, and W.M. Gelbart. 1991. Drosophila $60 \mathrm{~A}$ gene, a new TGF- $\beta$ family member is closely related to human bone morphogenetic proteins. Proc. Natl. Acad. Sci. 88: 9214-9218.

Wharton, K.A., R.P. Ray, and W.M. Gelbart. 1993. An activity gradient of decapentaplegic is necessary for the specification of dorsal pattern elements in the Drosophila embryo. Development 117: 807-822.

Wieschaus, E., C. Nüsslein-Volhard, and G. Jürgens. 1984. Mutations affecting the pattern of the larval cuticle in Drosophila melanogaster III. Zygotic loci on the X-chromosome and fourth chromosome. Wilhelm Roux's Arch. Dev. Biol. 193: 296-307.

Wieschaus, E. and C. Nüsslein-Volhard. 1986. Looking at embryos. In Drosophila: A practical approach (ed. D.B. Roberts), pp. 199-227. IRL Press, Oxford, UK.

Wozney, J.M. 1992. The bone morphogenetic family and osteogenesis. Mol. Reprod. Dev. 32: 160-167.

Wozney, J.M., V. Rosen, A.J. Celeste, L.M. Mitsock, M.J. Whitters, R.W. Kriz, R.M. Hewick, and E.A. Wang. 1988. Novel regulators of bone formation: Molecular clones and activities. Science 242: 1528-1534.

Yu, J., L. Shao, V. Lemas, A.L. Yu, J. Vaughan, J. Rivier, and W. Vale. 1987. Importance of FSH-releasing protein and inhibin in erythrodifferentiation. Nature 330: 765-767.

Zimmerman, J.L., W. Petri, and M. Meselson. 1983. Accumulation of a specific subset of $D$. melanogaster heat shock mRNAs in normal development without heat shock. Cell 32: $1161-1170$.

Zusman, S. and E. Wieschaus. 1985. Requirements for zygotic gene activity during gastrulation in Drosophila melanogaster. Dev. Biol. 111: 359-371. 


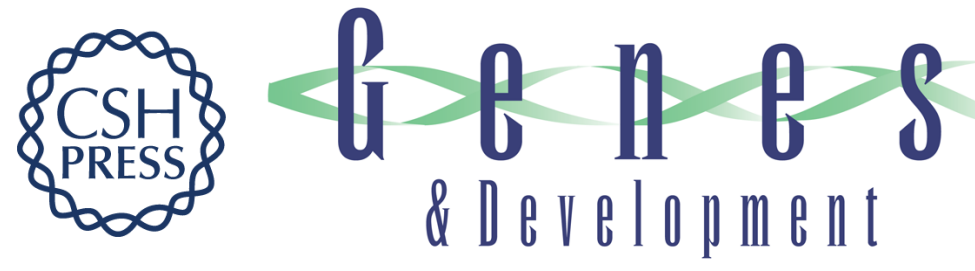

\section{The screw gene encodes a ubiquitously expressed member of the TGF-beta family required for specification of dorsal cell fates in the Drosophila embryo.}

K Arora, M S Levine and M B O'Connor

Genes Dev. 1994, 8:

Access the most recent version at doi:10.1101/gad.8.21.2588

References This article cites 73 articles, 26 of which can be accessed free at:

http://genesdev.cshlp.org/content/8/21/2588.full.html\#ref-list-1

License

Email Alerting

Service

Receive free email alerts when new articles cite this article - sign up in the box at the top right corner of the article or click here.

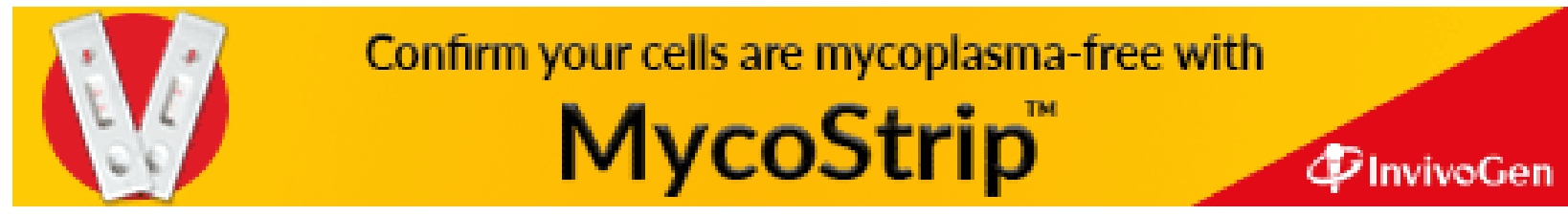

